\title{
Homocysteine as a non-classical risk factor for atherosclerosis in relation to pharmacotherapy of type $\mathbf{2}$ diabetes mellitus
}

\author{
Magdalena Borowska ${ }^{1 凶}$, Marzena Dworacka¹, Hanna Winiarska and Ewa Krzyżagórska² \\ 'Department of Pharmacology, University of Medical Sciences, Poznań, Poland; 2 Poznan Specialist Center of Medical Care, Diabetology Outpa- \\ tient Clinic, Poznań, Poland
}

\begin{abstract}
Aims. The aim of our study was to evaluate which of the pharmacotherapeutic methods that are frequently used to treat type 2 diabetes is associated with the most beneficial profile in relation to pro-atherogenic homocysteine levels. Patients and Methods. We measured the serum homocysteine level in 182 patients with type 2 diabetes treated with metformin (89), treated with insulin in combination with metformin (31), receiving sulfonylureas (31) and treated conventionally with insulin (31). The total homocysteine levels in the serum were assayed. To exclude the influence of selected metabolic and anthropometric factors on the differences between the examined groups, multivariate analysis of covariance was used (ANCOVA). In this analysis, serum homocysteine concentration was the dependent variable, while diabetes duration, waist circumference, $\mathrm{HbA}_{1 c^{\prime}}$ 1,5-anhydro-D-glucitol, fasting glycaemia and peptide $C$ were used as covariates. Results. The serum homocysteine levels in patients treated with insulin in monotherapy were significantly higher than what was observed in the metformin treated subjects and in the patients receiving insulin combined with metformin. The analysis of covariance also confirmed that the differences between the therapeutic groups were affected by waist circumference and the C-peptide levels. Conclusion. We conclude that conventional insulin therapy may have a negative effect on pro-atherogenic homocysteine levels in patients with type 2 diabetes. This study revealed that pro-atherogenic homocysteine levels may not only be modified by pharmacotherapy of type 2 diabetes, but also by beta cell secretory function and abdominal obesity.
\end{abstract}

Key words: homocysteine, atherosclerosis, type 2 diabetes

Received: 07 December, 2016; revised: 11 July, 2017; accepted: 27 August, 2017; available on-line: 07 December, 2017

$\$ e-mail: meg32@wp.pl

Abbreviations: Hcy, homocysteine; HHcy, hyperhomocysteinemia

\section{INTRODUCTION}

Numerous recent studies have clearly indicated that homocysteine can promote inflammation and atherosclerosis and thus increases the risk of cardiovascular disease and death. This relation seems to be stronger in subjects with diabetes, as compared to the general population (Becker et al., 2003; Guthikonda et al., 2006). Therefore, modern therapy regimens of diabetes should be effective both in optimizing glucose control and in the prevention of vascular complications through the modification of atherosclerosis risk factors including elevated homocysteine level. Serum homocysteine concentrations in healthy subjects are within the range of 5-15 $\mu \mathrm{mol} / \mathrm{L}$, a concentration exceeding the threshold for hyperhomocysteinemia may have an adverse effect on vascular endothelium (Baszczuk et al., 2014). Homocysteine-induced endothelium injury is due to the increased proliferation of vascular smooth muscle cells, as well as the increase in collagen synthesis and its deposition in the vascular wall (Pushpakumar et al., 2014). The vascular toxicity of homocysteine has been linked to the impaired endothelial production of nitric oxide, and the overproduction of oxidative radicals which induces intimal injury (Signorello et al., 2009). In addition, homocysteine occurring as a thiolactone, a highly reactive product of homocysteine oxidation, modulates gene expression in pathways important for vascular homeostasis and pathways linked to HHcy-induced endothelial dysfunction and the vascular disease (Gurda et al., 2015). Homocysteine auto-oxidation has been shown to generate the superoxide anion radicals that support the oxidation of low-density lipoproteins (Seo et al., 2010). In view of this pro-atherogenic effect, hyperhomocysteinemia is considered a very important modifiable risk factor for macroangiopathy (Becker et al., 2003).

Although the results of recent intervention studies have not proved any specific therapy to be advantageous or disadvantageous in terms of the impact on the incidence of major cardiovascular complications (U.K. Prospective Diabetes Study 1998, ADVANCED Trial 2008, Duckworth et al., 2009), it is known that metformin and insulin may secondarily influence the total serum homocysteine level in type 2 diabetes mellitus (Wile et al., 2010; Gallistl et al., 2000). The link between hyperhomocysteinemia and sulfonylureas therapy remains unknown. Therefore, the aim of this study was to compare the effect of the standard used anti-diabetic drugs, such as metformin, insulin in combination with metformin, sulfonylureas and conventional insulin therapy, on the cardiovascular risk factor such as hyperhomocysteinemia.

\section{MATERIALS AND METHODS}

Subjects. The study involved 182 people with type 2 diabetes treated for at least 6 months with one of the following treatment regimens: 89 patients treated with metformin (at a dose of 500-2550 mg daily), 31 patients treated with insulin in combination with metformin (3560 units insulin a day + metformin at a dose of 500 $2550 \mathrm{mg}$ daily), 31 patients treated with one of sulfonylureas such as gliclazide (at a dose of $30 \mathrm{mg}$ daily) or glimepiride (at a dose of 2-6 mg daily), 31 patients treated conventionally with insulin (a ready to use mixture of 35-60 insulin units a day). Each patient included in this study was also treated with statin (atorvastatin at a dose 
of $20 \mathrm{mg}$ daily or simvastatin 10-40 $\mathrm{mg}$ daily) and acetylsalicylic acid at antiplatelet doses, an angiotensin-converting enzyme inhibitor or sartan and with a selective beta-blocker. All subjects were Caucasian. The participants were identified as the outpatients of general practitioners in Poznan (Poland). The clinical and metabolic characteristics of all subjects are shown in Table 1 . Before the participants were eligible for the study, a complete physical and laboratory evaluation was performed. Type 2 diabetes was diagnosed according to the ADA and ESC/EASD criteria (American Diabetes Association 2007; European Society of Cardiology and of the European Association for the Study of Diabetes 2007). Patients with a history of infections, severe inflammatory diseases, renal failure, liver failure, heart failure, thyroid dysfunction, anaemia and patients receiving folic acid, vitamin $\mathrm{B}_{6}$ and vitamin $\mathrm{B}_{12}$ were excluded from this study.

Measurements. All blood samples for the measurement of various general and metabolic factors were obtained after 10 hours of overnight fasting and before administration of the morning dose(s) of medication. The biological materials analyzed were whole blood, plasma and serum.

Blood samples were collected from each patient and the fasting glucose levels in plasma, lipids in the serum and glycosylated hemoglobin $\left(\mathrm{HbA}_{1 \mathrm{c}}\right)$ in whole blood were determined immediately after collection. Serum samples for homocysteine, resistin, insulin, C-peptide and 1,5-AG levels were collected and stored at $-80^{\circ} \mathrm{C}$ until assay.

The total homocysteine levels in the serum were assayed using commercial kits (Axis ${ }^{\circledR}$ Human Homo- cysteine ELISA Kit, IBL). The reference range was 5-15 $\mu \mathrm{mol} / \mathrm{L}$.

The plasma concentrations of 1,5-Anhydro-D-glucitol (1,5-AG) were measured using a modified-column enzymatic method (Yabuuchi et al., 1984). The reference range was $14.4-30.2 \mathrm{mg} / 1$ (Dworacka et al., 2005).

The fasting serum insulin levels and concentrations of C-peptide were determined with commercially available immunoenzymatic ELISA kits.

Statistical analysis. Results are expressed as median and mean \pm S.E.M. A comparison of variables between the examined groups was performed using ANOVA (parametric distribution) or with the Kruskall-Wallis test (non-parametric distribution). To exclude the influence of selected factors on the differences between the examined groups, a multivariate analysis of covariance was used (ANCOVA). In this analysis, serum homocysteine concentration was the dependent variable, while the diabetes duration, waist circumference, $\mathrm{HbA}_{1 \mathrm{c}}, 1,5-\mathrm{AG}$, fasting glycaemia and C-peptide were used as covariates. The relationships between variables were analyzed by calculating Spearman's $p$ statistic. All statistical analyses were performed using Statistica 6.0 (StatSoft, Inc.). A $p$-value $\leq 0.05$ was considered to be statistically significant.

\section{RESULTS}

Table 1 shows the characteristics of the subjects with type 2 diabetes. All patients were similar in terms of age and lipid profiles. Patients treated with metformin differed in the duration of diabetes and had a lower $\mathrm{HbA}_{1 \mathrm{c}}$ than other therapeutic groups. Fasting glycaemia was significantly

Table 1. The clinical characteristics of patients with type 2 diabetes varying in the type of pharmacotherapy (Kruskal-Wallis)

\begin{tabular}{|c|c|c|c|c|}
\hline & $\begin{array}{l}\text { Metformin } \\
\text { Median/mean } \pm S . D \text {. } \\
n=89\end{array}$ & $\begin{array}{l}\text { Insulin } \\
+ \text { metformin } \\
\text { Median/mean } \pm \text { S.D. } \\
n=31\end{array}$ & $\begin{array}{l}\text { Sulfonylurea } \\
\text { Median/mean } \pm S . D \text {. } \\
n=31\end{array}$ & $\begin{array}{l}\text { Insulin } \\
\text { Median/mean } \pm \text { S.D. } \\
\mathrm{n}=31\end{array}$ \\
\hline $\mathrm{F} / \mathrm{M}$ & $47 F / 42 M$ & $13 \mathrm{~F} / 18 \mathrm{M}$ & $14 \mathrm{~F} / 17 \mathrm{M}$ & $15 \mathrm{~F} / 16 \mathrm{M}$ \\
\hline Age [years] & $62 / 61.2 \pm 8.9$ & $60 / 61.4 \pm 8.8$ & $68 / 67.1 \pm 12.1$ & $63 / 65.0 \pm 10.0$ \\
\hline Diabetes duration [years] & $4 / 5.0 \pm 5.0^{a}$ & $9 / 10.8 \pm 8.7$ & $7 / 9.7 \pm 7.5$ & $9 / 11.2 \pm 7.9$ \\
\hline BMI $\left[\mathrm{kg} / \mathrm{m}^{2}\right]$ & $30.6 / 31.3 \pm 5.3$ & $32.8 / 34.9 \pm 6.9$ & $30.5 / 31.8 \pm 7.6$ & $32 / 35.4 \pm 11.1$ \\
\hline Waist circumference $[\mathrm{cm}]$ & $103 / 103,79 \pm 10,8^{b, c}$ & $109 / 110,19 \pm 12,4$ & $118 / 116,19 \pm 10,8$ & $117 / 115,06 \pm 13,9$ \\
\hline Fasting glycaemia (mg/dl) & $126.0 / 129.6 \pm 28.3^{b, c}$ & $137.0 / 148.4 \pm 45.5$ & $148.0 / 160.1 \pm 48.5$ & $157.5 / 176.3 \pm 60.3$ \\
\hline Total cholesterol (mg/dl) & $201.0 / 201.7 \pm 46.3$ & $188.0 / 190.0 \pm 47.6$ & $226.0 / 217.8 \pm 53.2$ & $196.8 / 200.4 \pm 53.0$ \\
\hline LDL Cholesterol (mg/dl) & $119.0 / 118.8 \pm 37.3$ & $110.0 / 110.6 \pm 39.6$ & $120.0 / 119.6 \pm 39.6$ & $104.3 / 105.6 \pm 42.3$ \\
\hline HDL Cholesterol (mg/dl) & $47.0 / 50.2 \pm 14.4$ & $44.0 / 44.3 \pm 9.6$ & $54.0 / 53.4 \pm 13.5$ & $42.0 / 47.4 \pm 14.7$ \\
\hline $\begin{array}{l}\text { Triglycerides } \\
(\mathrm{mg} / \mathrm{dl})\end{array}$ & $150.0 / 173.9 \pm 94.5$ & $164.7 / 190.2 \pm 90.1$ & $147.0 / 206.3 \pm 154.7$ & $162.0 / 188.5 \pm 113.7$ \\
\hline $\begin{array}{l}\mathrm{HbA}_{1 \mathrm{c}}(\%) \\
{[\mathrm{mmol} / \mathrm{mol}]}\end{array}$ & $\begin{array}{l}6.6 / 6.7 \pm 1.1^{a} \\
49.5 / 50.1 \pm 12.0\end{array}$ & $\begin{array}{l}7.5 / 7.7 \pm 1.4 \\
60 / 60.6 \pm 15.6\end{array}$ & $\begin{array}{l}7.3 / 7.6 \pm 1.8 \\
55.5 / 59.6 \pm 19.6\end{array}$ & $\begin{array}{l}8.0 / 8.3 \pm 1.2 \\
66 / 67.2 \pm 13.3\end{array}$ \\
\hline $1.5-\mathrm{AG}(\mathrm{mg} / \mathrm{L})$ & $16.4 / 15.6 \pm 5.9 c$ & $12.4 / 12.5 \pm 6.1$ & $13.5 / 14.3 \pm 6.7 c$ & $8.5 / 9.4 \pm 4.2$ \\
\hline $\mathrm{HOMA}_{\mathrm{IR}}$ & $2.1 / 2.9 \pm 2.4$ & - & $2.7 / 3.1 \pm 2.2$ & - \\
\hline Insulin (pmol/L) & $39.5 / 53.0 \pm 38.2$ & - & $42.5 / 47.6 \pm 33.5$ & - \\
\hline C-peptide (ng/ml) & $2.6 / 2.8 \pm 1.3^{c}$ & $2.0 / 2.2 \pm 1.5$ & $1.87 / 2.2 \pm 1.8$ & $1.2 / 1.4 \pm 0.9$ \\
\hline
\end{tabular}

$M$, males; $F$, females. astatistically significant difference compared to every other group for $p \leq 0.05$. bstatistically significant difference compared to the sulfonylurea treated group for $p \leq 0.05$. cstatistically significant difference compared to the insulin treated group for $p \leq 0.05$ 
Table 2. Comparison of homocysteine concentrations among the examined therapeutic groups (Kruskal-Wallis)

\begin{tabular}{llll}
\hline & $\begin{array}{l}\text { Metformin } \\
\text { Median/mean } \pm \text { S.D. } \\
\mathrm{n}=89\end{array}$ & $\begin{array}{l}\text { Insulin } \\
+ \text { metformin } \\
\text { Median/mean } \pm \text { S.D. } \\
\mathrm{n}=31\end{array}$ & $\begin{array}{l}\text { Sulfonylurea } \\
\text { Median/mean } \pm \text { S.D. } \\
\mathrm{n}=31\end{array}$ \\
\hline F/M & $47 / 42$ & $13 / 18$ & $\begin{array}{l}\text { Insulin } \\
\mathrm{n}=31\end{array}$ \\
Homocysteine $[\mu \mathrm{mol} / \mathrm{L}]$ & $10.9 / 12.8 \pm 7.4$ & $14.5 / 13$ & $15 / 16$ \\
\hline
\end{tabular}

F, females; M, males. * statistically significant difference compared to every other group for $p \leq 0.05$

lower in the metformin-treated group than in patients receiving sulfonylurea or the patients treated with insulin in monotherapy. The plasma 1,5-AG concentrations were significantly higher in the subjects treated with metformin and in those treated with sulfonylurea than in those treated with insulin in monotherapy, whereas the fasting serum C-peptide levels were higher than in the insulin-treated group only in the patients receiving metformin.

When analyzing the differences in the homocysteine serum level among the therapeutic groups of diabetic patients, it was found that the concentrations of the homocysteine level in patients treated with insulin in monotherapy were significantly higher than those observed for every other therapeutic group $(p \leq 0.05)$, which did not vary among themselves in this respect (Table 2).

The analysis of covariance confirmed the inter-group differences in the homocysteine concentrations $(p \leq 0.05)$ (Fig. 1) and revealed that these differences were affected not only by the method of treatment $[\mathrm{F}=14.5, p \leq 0.001]$ but also by the waist circumference $[\mathrm{F}=5.1, p=0.03]$ and the C-peptide levels [F=18.4, $p=0.01]$.

The most significant positive correlation was observed between the serum concentrations of homocysteine and waist circumference $[\mathrm{r}=0.30 ; p \leq 0.05]$.

\section{DISCUSSION}

The results of many studies clearly point to the participation of hyperhomocysteinemia in the progression

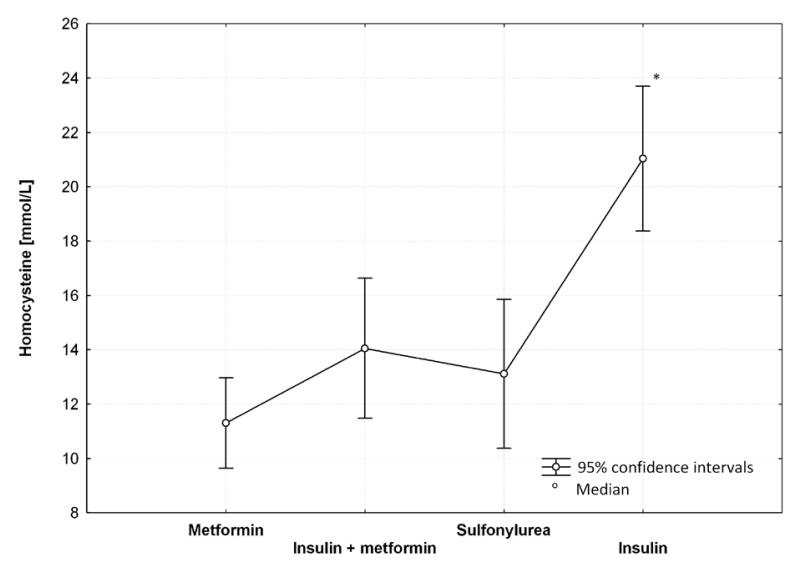

Figure 1. Results of ANCOVA considering the impact of metabolic and anthropometric parameters on homocysteine concentrations among patients with type 2 diabetes varying in the type of pharmacotherapy.

Vertical columns represent confidence intervals, with the following average concomitant variables: diabetes duration -7.8 years, waist circumference $-108.5 \mathrm{~cm}, \mathrm{HbA} 1 \mathrm{c}-7.4 \%$, fasting glycaemia - $147.1 \mathrm{mg} / \mathrm{dl}$, 1.5-AG - $13.9 \mathrm{mg} / \mathrm{L}$, peptide C - $2.4 \mathrm{ng} / \mathrm{ml}$; * ${ }^{*}$ tatistically significant difference compared to the group treated with metformin, group treated with metformin + insulin and group treated with sulfonylureas for $p \leq 0.05$ of atherosclerotic changes in type 2 diabetes patients. Previous reports on the effects of anti-diabetic drugs on homocysteine levels refer only to metformin and insulin, analyzing these therapeutic groups separately (Wile et al., 2010; Jager et al., 2010; Mohammadi et al., 2009; Björck et al., 2006; Gallistl et al., 2000). Therefore, the aim of our study was to carry out a comparative analysis of different therapeutic groups in terms of homocysteine concentrations in the serum. This study showed that the use of conventional insulin therapy was related to higher homocysteine levels in the treated patients than in patients receiving oral antidiabetic drugs. At first glance, these results are surprising in the light of current knowledge, especially as far as metformin is concerned. It has been confirmed that metformin has the ability to induce high levels of homocysteine and may be a causative factor for hyperhomocysteinemia (Refsum et al., 2004; Sato et al., 2013). The relationship between hyperhomocysteinemia and metformin has been documented in numerous studies, but the strength of this relation was different in different experiments (Refsum et al., 2004; Sato et al., 2013; Dierkes et al., 2005; Valdés-Ramos et al., 2015). It is known that metformin promotes hyperhomocysteinemia primarily by inhibiting the absorption of vitamin B12 in the intestines (Valdés-Ramos et al., 2015). Unexpectedly low levels of homocysteine in the examined group of patients receiving metformin could result from the fact that the resources of endogenous vitamin $B_{12}$ were sufficient to ensure the proper conduct of the remethylation of homocysteine to methionine, despite the negative impact of metformin on the absorption of vitamin $\mathrm{B}_{12}$. The patients in the treatment group received metformin according to the research protocol for at least six months prior to testing, but for most of them, the total duration of treatment with metformin was not longer than six months and perhaps it was too short a period for the depletion of endogenous vitamin $B_{12}$. Similar conditions accompanied the use of metformin in patients treated with insulin in combination with metformin. The development of vitamin $\mathrm{B}_{12}$ deficiency over a relatively short period of time is highly unlikely, and perhaps, to some extent, it explains the lack of adverse effects of metformin in the study presented here. At the same time, it would be wrong to state that metformin has as a particularly positive effect on the levels of homocysteine in the blood.

The explanation as to why, among the compared methods of therapy, a conventional insulin therapy has resulted in the least beneficial serum homocysteine levels and, what is more, why only this type of pharmacotherapy is related to the occurrence of hyperhomocysteinemia, should be sought in the type of metabolic transformations in which homocysteine and insulin take part. Results that are similar to the ones presented here were previously presented by Jacobs who tested animal diabetes and has shown that the application of human ultralente insulin analogue leads to an increase in the blood ho- 
mocysteine level (Jacobs et al., 1998). The author claims that the reason for such change was the influence of insulin on the decrease of cystathionin-beta synthase activity which is responsible for the transsulfuration process in the liver which eventually leads to an increase in the homocysteine level. However, Ratman and coworkers (2002) had demonstrated that, in the course of diabetes, homocysteine catabolism in the liver is more intensified and its decreased level is therefore obvious. It is only exposure to exogenous insulin that reverses this phenomenon, i.e. stops homocysteine catabolic transformations resulting in a decrease in catabolic enzymes' activity, favoring at the same time an increase in the amount of homocysteine and its blood level. Hence, it should be concluded that the modeling of insulin-dependent Hcy levels is a function of insulin concentration in the blood. This fact may explain the lack of influence of sulfonylurea derivatives on the homocysteine concentrations in our study. Although the drugs in this group exacerbate insulin secretion by beta cells, it can be expected that their effect should include inhibiting homocysteine catabolism and increasing its blood concentration. However, it seems that insulinemia thus obtained is insufficient to induce changes in the expression of cystathionin-beta synthase and consequently to make changes in the concentrations of the Hcy. The results of the covariance analysis in our study indicate that along with pharmacotherapy, it is also waist circumference and C-peptide levels that determine the differences in homocysteine concentrations between the treatment groups. Similar results were obtained by Vayá and coworkers (2012) in a study were increased Hcy levels were associated mostly with the abdominal obesity and with insulin resistance. The mechanism explaining the link between hyperhomocysteinemia and obesity is not clear, but there is evidence that obesity may be accompanied by a deficiency in folate that is the source of methyl groups necessary for the remethylation of homocysteine to methionine (Nakazato et al., 2011; Mojtabai 2004). In this way, folate deficiency in obesity contribute to the inhibition of homocysteine catabolism leading to an increase in its concentration. In turn, other interesting scientific studies underline the genetic polymorphism of MTHFR as a predisposing factor for hyperhomocysteinemia and obesity (Bazzaz et al., 2010). The Chakraborty study (2015) highlighted the relationship between the polymorphism of the MTHFR gene and homocysteine homogeneity in patients with type 2 diabetes and demonstrated that the increase in homocysteine level was determined by an individual genotype. The genetic polymorphism of MTHFR may also be a factor responsible for the occurrence of serious vascular complications in type 2 diabetes (Fekih-Mrissa et al., 2017; Chehadeh et al., 2015). Although the genetic aspect of hyperhomocysteinemia was not the subject of our study, the possible occurrence of MTHFER genetic polymorphism as a factor modulating homocysteine levels should be taken into consideration.

In conclusion, we observed that among the studied therapeutic regimens only conventional insulin therapy was the unfavorable treatment method in terms of its impact on the homocysteine levels. Nevertheless, the homocysteine concentrations may also be affected by other factors like $\beta$ cell function and the presence of abdominal obesity. This is why we can speculate that the level of homocysteine needs to be analyzed as a final result of the influence of several factors, including pharmacotherapy, inflammatory process, anthropometric alterations and genetic factors.

\section{Conflict of interest}

The authors declare that they have no conflict of interest.

\section{Ethical standard}

The Ethics Committee of the University of Medical Sciences approved the protocol of this study.

\section{Acknowledgements}

This study was supported by grant No 402357638 from the Polish Ministry of Science and Higher Education, Warsaw, Poland.

\section{REFERENCES}

ADVANCE Collaborative Group Intensive blood glucose control and vascular outcomes in patients with type 2 diabetes (2008) N Engl J Med 358: 2560-2572

American Diabetes Association. Standards of medical care in diabetes - 2007. Diabetes Care 30: 4-41

Baszczuk A, Kopczynski Z (2014) Hyperhomocysteinemia in patients with cardiovascular disease. Postep Hig Med Dosw 68: 579. doi: 10.5604/17322693.1102340

Bazzaz JT, Shojapoor M, Nazem H, Amiri P, Fakhrzadeh H, Heshmat R, Parvizi M, Ranjbar SH, Amoli MM (2010) Methylenetetrahydrofolate reductase gene polymorphism in diabetes and obesity. Mol Biol Rep 37: 105-109. doi: 10.1007/s11033-009-9545-z

Becker A, Smulders YM, van Guldener C (2003) Epidemiology of homocysteine as a risk factor in diabetes. Metab Syndr Relat Disord 1: 105-120. DOI: 10.1089/154041903322294434

Björck J, Hellgren M, Råstam L, Lindblad U (2006) Associations between serum insulin and homocysteine in a Swedish population - a potential link between the metabolic syndrome and hyperhomocysteinemia: The Skaraborg project. Metab Clin Exp 55: 1007-1013. doi: http://dx.doi.org/10.1016/j.metabol.2006.03.010

Chakraborty A, Chakraborty A, Chowdhury S, Sengupta S, Bhattacharyya M (2015) Association of MTHFR $677 \mathrm{C}>\mathrm{T}$ genetic polymorphism with hyperhomocysteinemia in type 2 diabetes patients. Cogent Medicine 2: 1017973

Chehadeh SW, Jelinek HF, Al Mahmeed WA, Tay Guan K, Odama UO, Elghazali GEB, Al Safar HS (2016) Relationship between MTHFR C677T and A1298C gene polymorphisms and complications of type 2 diabetes mellitus in an Emirati population. Meta Gene 9: $70-75$

Dierkes J, Westphal S. Effect of drugs on homocysteine concentrations (2005) Semin V asc Med 5: 124-139. doi: 10.1055/s-2005-872398

Duckworth W, Abraira C, Moritz T, Reda D, Emanuele N, Reaven PD, Zieve FJ, Marks J, Davis SN, Hayward R, Warren SR, Goldman S, McCarren M, Vitek M, Henderson WG, Huang GD, MPH (2009) Glucose control and vascular complications in veterans with type 2 diabetes. N Engl J Med 360: 129-139. doi: 10.1056/NEJMoa0808431

Dworacka M, Winiarska H (2005) The application of plasma 1.5-anhydro-D-glucitol for monitoring type 2 diabetic patients. Dis Markers 21: $127-132$

European Society of Cardiology (ESC) and of the European Association for the Study of Diabetes (EASD). Guidelines on diabetes, pre-diabetes, and cardiovascular diseases: executive summary. The Task Force on Diabetes and Cardiovascular Diseases of the European Society of Cardiology (ESC) and of the European Association for the Study of Diabetes (EASD) (2007). Eur Heart J 28: 88-136

Fekih-Mrissa N, Mrad M, Ibrahim H, Akremi I, Sayeh A, Jaidane A, Ouertani H, Zidi B, Gritli N (2017) Methylenetetrahydrofolate reductase (MTHFR) (C677T and A1298C) polymorphisms and vascular complications in patients with type 2 diabetes. Can J Diabetes 21: 1499-2671. doi: 10.1016/j.jcjd.2016.11.007

Gallistl S, Sudi K, Mangge H, Gallistl S, Sudi K, Mangge H (2000) Insulin is an independent correlate of plasma homocysteine levels in obese children and adolescents. Diabetes Care 23: 1348-1352

Gurda D, Handschuh L, Kotkowiak W, Jakubowski H (2015) Homocysteine thiolactone and $\mathrm{N}$-homocysteinylated protein induce pro-atherogenic changes in gene expression in human vascular endothelial cells. Amino Acids 47: 1319-1339. doi: 10.1007/s00726015-1956-7

Guthikonda S, Haynes WG (2006) Homocysteine: role and implications in atherosclerosis. Curr Atheroscler Rep 8: 100-106

Jacobs RL, House JD, Brosnan ME, Brosnan JT (1998) Effects of streptozotocin-induced diabetes and of insulin treatment on homocysteine metabolism in the rat. Diabetes 47: 1967-1970 
Jager J, Kooy A, Lehert P, Wulffelé MG, van der Kolk J, Bets D, Verburg J, Donker AJ, Stehouwer CD (2010) Long term treatment with metformin in patients with type 2 diabetes and risk of vitamin B-12 deficiency: randomised placebo controlled trial. BMJ 340: 2181. doi: https://doi.org/10.1136/bmj.c2181

Mohammadi M, Amini M, Aminiorroay A, Rezvanian H, Kachuei A, Siyavash M, Saghand SR, Afkhami-Ardekani M (2009) Effect of metformin and folic acid on plasma homocysteine level in type 2 diabetic patients. Int J Med Med Sci 3: 88-90

Mojtabai R (2004) Body mass index and serum folate in childbearing age women. Eur I Epidemiol 19: 1029-1036

Nakazato M, Maeda T, Takamura N, Wada M, Yamashita H, Johnston KE, Tamura T (2011) Relation of body mass index to blood et al. (2011) Relation of body mass index to blood folate and total homocysteine concentrations in Japanese adults. Eur J Nutr 50: 581-585

Pushpakumar S, Kundu S, Sen U (2014) Endothelial dysfunction: the link between homocysteine and hydrogen sulfide. Curr Med Chem 21: 3662-3672

Ratman S, Maclean KN, Jacobs RL, Brosnan ME, Kraus JP, Brosnan JT (2002) Hormonal regulation of cystathionine-synthase expression in liver. I Biol Chem 277: 42912-42918. doi: 10.1016/S22150366(14)00081-9

Refsum H, Smith AD, Ueland M, Nexo E, Clarke R, McPartlin J, Johnston C, Engbaek F, Schneede J, McPartlin C, Scott JM (2004) Facts and recommendations about total homocysteine determinations: an expert opinion. Clin Chem Acta 50: 3-32. doi: 10.1373/ clinchem.2003.021634

Sato Y, Ouchi K, Funase Y, Yamauchi K, Aizawa T (2013) Relationship between metformin use, vitamin B12 deficiency, hyperhomo- cysteinemia and vascular complications in patients with type 2 diabetes. Endocr J 60: 1275-1280

Seo H, Oh H, Park H, Park M, Jang Y, Lee M (2010) Contribution of dietary intakes of antioxidants to homocysteine-induced low density lipoprotein (LDL) oxidation in atherosclerotic patients. Yonsei Med J 51: 526-533. doi: 10.3349/ymj.2010.51.4.526

Signorello MG, Segantin A, Passalacqua M, Leoncini G (2009) Homocysteine decreased platelet $\mathrm{NO}$ level via protein kinase $\mathrm{C}$ activation. Nitric Oxide 20: 104-113. doi: 10.1016/j.niox.2008.11.005

U.K. Prospective Diabetes Study Group Intensive blood-glucose control with sulphonylureas or insulin compared with conventional treatment and risk of complications in patients with type 2 diabetes (UKPDS 33) (1998) Lancet 352: 837-853

Valdés-Ramos R, Guadarrama-López AL, Martínez-Carrillo BE, Benítez-Arciniega AD (2015) Vitamins and type 2 diabetes mellitus. Endocr Metab Immune Disord Drug Targets 15: 54-63

Vayá A, Rivera L, Hernández-Mijares A, de la Fuente M, Solá E, Romagnoli M, Alis R, Laiz B (2012) Homocysteine levels in morbidly obese patients: its association with waist circumference and insulin resistance. Clin Hemorbeol Microcirc 52: 49-56. doi: 10.3233/CH-20121544

Wile DJ, Toth C (2010) Association of metformin, elevated homocysteine, and methylmalonic acid levels and clinically worsened diabetic peripheral neuropathy. Diabetes Care 33: 156-161. doi: 10.2337/ dc09-0606

Yabuuchi M, Masuda M (1984) Simple enzymatic method for determining 1,5-anhydro-D-glucitol for diagnosis of diabetes mellitus. Clin Chem 35: 2039-2043 